\title{
Concurrent use of diuretics, angiotensin converting enzyme inhibitors, and angiotensin receptor blockers with non-steroidal anti-inflammatory drugs and risk of acute kidney injury: nested case-control study
}

\author{
(c) $\frac{(1)(8)}{\mathrm{gy}}$ MPEN ACCESS
}

\author{
Francesco Lapi pharmacoepidemiology fellow ${ }^{123}$, Laurent Azoulay assistant professor ${ }^{14}$, Hui Yin \\ statistician $^{1}$, Sharon J Nessim assistant professor and nephrologist specialist ${ }^{5}$, Samy Suissa \\ professor and director $^{12}$
}

${ }^{1}$ Centre for Clinical Epidemiology, Lady Davis Institute, Jewish General Hospital, 3755 Côte Sainte-Catherine Montreal, Quebec, Canada, H3T 1E2; ${ }^{2}$ Department of Epidemiology, Biostatistics and Occupational Health, McGill University, Montreal, Quebec, Canada, H3A 1A2; ${ }^{3}$ Department of Preclinical and Clinical Pharmacology, University of Florence, 50139 Florence, Italy; ${ }^{4}$ Department of Oncology, McGill University, Montreal, Quebec, Canada, H3G 1A4; ${ }^{5}$ Department of Medicine, Division of Nephrology, Jewish General Hospital, Montreal, Quebec, Canada, H3T 1E2

\begin{abstract}
Objectives To assess whether a double therapy combination consisting of diuretics, angiotensin converting enzyme inhibitors, or angiotensin receptor blockers with addition of non-steroidal anti-inflammatory drugs (NSAIDs) and the triple therapy combination of two of the aforementioned antihypertensive drugs to which NSAIDs are added are associated with an increased risk of acute kidney injury.

Design Retrospective cohort study using nested case-control analysis.

Setting General practices contributing data to the UK Clinical Practice Research Datalink linked to the Hospital Episodes Statistics database.

Participants A cohort of 487372 users of antihypertensive drugs.

Main outcome measures Rate ratios with $95 \%$ confidence intervals of acute kidney injury associated with current use of double and triple therapy combinations of antihypertensive drugs with NSAIDs.

Results During a mean follow-up of 5.9 (SD 3.4) years, 2215 cases of acute kidney injury were identified (incidence rate $7 / 10000$ person years). Overall, current use of a double therapy combination containing either diuretics or angiotensin converting enzyme inhibitors or angiotensin receptor blockers with NSAIDs was not associated with an increased rate of acute kidney injury. In contrast, current use of a triple therapy combination was associated with an increased rate of acute kidney injury (rate ratio $1.31,95 \%$ confidence interval 1.12 to 1.53 ). In secondary analyses, the highest risk was observed in the first 30 days of use (rate ratio $1.82,1.35$ to 2.46 ).
\end{abstract}

Conclusions A triple therapy combination consisting of diuretics with angiotensin converting enzyme inhibitors or angiotensin receptor blockers and NSAIDs was associated with an increased risk of acute kidney injury. The risk was greatest at the start of treatment. Although antihypertensive drugs have cardiovascular benefits, vigilance may be warranted when they are used concurrently with NSAIDs.

\section{Introduction}

Acute kidney injury is a major clinical concern. According to the World Health Organization's most recent estimates (2009), the incidence rate of hospital admissions related to acute kidney in the United Kingdom is 5 per 10000 residents. ${ }^{1}$ Furthermore, among people admitted to hospital with acute kidney injury requiring dialysis support, the incidence rate of mortality related to acute kidney injury can exceed $50 \% .^{2-6}$

Adverse reactions to drugs remain an important cause of acute kidney injury. Kidneys regulate the excretion of almost all drugs, which, in turn, may lead to nephropathy. ${ }^{7}$ In England, the rate of hospital admission for drug induced nephropathy increased almost twofold between 1999 and 2009. ${ }^{8}$

Although drug related acute kidney injury is commonly associated with the use of individual classes of drugs (such as antiretroviral drugs, aminoglycoside antibiotics, and non-steroidal anti-inflammatory drugs (NSAIDs)), ${ }^{9-13}$ little is known about the effects of drug-drug interactions on this outcome. This aspect is particularly relevant among users of antihypertensive drugs, who often need more than one drug for adequate blood pressure control. For example, in patients with heart failure and hypertension, the concurrent use of angiotensin 
converting enzyme inhibitors or angiotensin receptor blockers along with diuretics is common. ${ }^{14-16}$ However, many of these patients also have chronic inflammatory diseases or chronic pain, so the add-on use of NSAIDs may be indicated.

Some case reports and pharmacovigilance analyses have suggested that the concurrent use of diuretics, angiotensin converting enzyme inhibitors, or angiotensin receptor blockers with NSAIDs can increase the risk of acute kidney injury. ${ }^{17-19}$ This risk is thought to vary with the number of antihypertensive drug classes used concurrently with NSAIDs. Specifically, patients can be exposed to a double or triple therapy combination composed of one or two of the aforementioned antihypertensive drug classes with NSAIDs.

From a pharmacological perspective, these combinations may increase the risk of acute kidney injury, as each has the potential to affect kidney function through different mechanisms. Use of diuretics can lead to hypovolaemia, angiotensin converting enzyme inhibitors/angiotensin receptor blockers cause a haemodynamic reduction in glomerular filtration rate due to efferent arteriolar vasodilation, and NSAIDs cause inhibition of prostacyclin synthesis (leading to renal afferent arteriolar vasoconstriction). ${ }^{712} 172021$

To our knowledge, only one observational study has specifically investigated the risk of acute kidney injury associated with the use of these drug combinations. ${ }^{17}$ An increased risk was observed in that study, but the study was limited by its cross sectional design and possible confounding by indication and severity (as heart failure is an independent predictor of acute kidney injury ${ }^{22}$ ). Furthermore, the authors used mean values of blood creatinine concentrations to define the study outcome, without using a specific cut-off that is needed to identify cases of acute kidney injury. ${ }^{17}$ Given the limited safety data on the aforementioned combinations, we conducted a large population based study to determine whether the use of diuretics and/or angiotensin converting enzyme inhibitors or angiotensin receptor blockers with NSAIDs is associated with an increased risk of acute kidney injury.

\section{Methods}

\section{Data sources}

This study was carried out using the Clinical Practice Research Datalink (CPRD), previously known as the General Practice Research Database, and the Hospital Episodes Statistics repository from the UK.

The CPRD is the world's largest computerised database of longitudinal records from primary care. The data recorded in the CPRD since 1987 include demographic information, prescription details, clinical events, specialist referrals, and deaths. ${ }^{23}$ In addition, the CPRD collects information on lifestyle variables such as body mass index and data on smoking and excessive alcohol use. The Read code classification is used to enter medical diagnoses and procedures, and a coded drug dictionary based on the UK Prescription Pricing Authority Dictionary is used for recording prescriptions. Recent reviews of all validation studies found that medical data in the CPRD are of high quality. ${ }^{24}$

In addition, patients in the CPRD can now be linked individually and anonymously to the UK national registry of hospital admissions (Hospital Episode Statistics repository). The linkages are made by using the unique National Health Service identifier, date of birth, sex, and postcode of patients. Since 1997, the repository contains dates of hospital admission, discharge diagnosis (coded using ICD-10 (international classification of diseases, 10th revision)), and related procedures (coded using ICD-10 and OPCS-4 (Office of Population Censuses and Surveys classification of interventions and procedures, 4 th version)).

\section{Study population}

Within the CPRD population, we assembled a cohort of patients who received antihypertensive drugs between 1 January 1997 and 31 December 2008, with follow-up until 31 December 2010. For the purposes of this study, cohort entry was the date of a first prescription for any antihypertensive drug (diuretics, angiotensin converting enzyme inhibitors, angiotensin receptor blockers, calcium channel blockers, $\alpha$ and $\beta$ blockers) during the study period. Patients were required to have at least one year of up to standard medical history in the CPRD before that first prescription. For patients with less than one year of registration with the general practice at the time of their first prescription, we moved their cohort entry date forward in time to allow a minimum one year medical history before the cohort entry. We excluded patients with a history of any cancer, renal disorders (history of chronic kidney disease, acute kidney injury, or both, including dialysis related procedures), hepatitis, systemic connective tissue diseases, rheumatoid arthritis, crush injury, HIV infection, and any drug misuse at any time before cohort entry. We followed all patients who met the study inclusion criteria until a first ever hospital admission for acute kidney injury, the occurrence of one of the exclusion criteria (including hospital admission for acute kidney injury in secondary diagnosis position, or dialysis related procedures when they were not followed (within 30 days) by a diagnosis of acute kidney injury in primary position), death from any cause, end of registration with the general practice, or end of the study period (31 December 2010), whichever occurred first.

\section{Selection of cases and controls}

We defined cases by the first ever occurrence of a hospital admission related to acute kidney injury during follow-up, using the Hospital Episodes Statistics database (identified by using the ICD-10 diagnostic codes N17, N17.0-2, N17.8-9 in primary position). Among these cases, we also identified those that required dialysis during their hospital admission. ${ }^{26}{ }^{27}$ As dialysis may precede or follow a diagnosis of acute kidney injury, we searched for procedure codes within 30 days before or after the admission date (ICD-10 codes Z99.2, Z49.0, Z49.1; OPCS-4 codes X40.1,3,8,9, X41.8,9, X42.8,9, X43.1); the index date was the earliest date of either the admission for acute kidney injury or the dialysis procedure.

Up to 10 controls were randomly selected and matched to each case on year of birth (age), sex, calendar year of cohort entry, prevalent user status (that is, patients for whom cohort entry was moved forward in time to allow at least one year of registration in the general practice), and duration of follow-up. Thus, all controls were alive, not previously diagnosed as having acute kidney injury, registered with their general practice when matched to a given case, and had an equal duration of follow-up at the risk set date. The date of the risk set was the index date for the controls.

\section{Exposure assessment}

For all cases and controls, we obtained information on all drugs prescribed between cohort entry and the index date, including diuretics, angiotensin converting enzyme inhibitors, angiotensin receptor blockers, and NSAIDs. We defined a double therapy combination as the concurrent use of either diuretics, angiotensin 
converting enzyme inhibitors, or angiotensin receptor blockers with NSAIDs. We defined a triple therapy combination as the concurrent use of diuretics and angiotensin converting enzyme inhibitors or angiotensin receptor blockers, along with NSAIDs. To be considered a double or triple therapy combination, the drugs of interest had to have been prescribed on the same day or, alternatively, their specified durations of use had to overlap each other for at least one day during follow-up. We calculated this by using the number of prescribed tablets combined with dosing instructions and daily dose. We divided the number of prescribed units by the daily dose to obtain the expected duration of drug use. For the antihypertensive drugs, we defined continuous use as when the duration of one prescription overlapped the date of the next prescription, allowing for a 90 day grace period between prescriptions (a grace period determined by both the pharmacokinetics and prescribing patterns of these drugs in general practice ${ }^{28}$ ). For NSAIDs, continuous use was similarly defined, but the grace period consisted of the half life of the drug. In the special situation in which patients were prescribed more than one NSAID, we used the one with the longest half life to determine the overlap with the antihypertensive drugs.

On the basis of the above, we classified patients into one of three mutually exclusive groups: "current use," defined as a double or triple therapy combination overlapping the 90 days immediately before the index date; "past use," defined as a combination after cohort entry but ending before the 90 days before the index date; and "never use," defined as the absence of a double or triple therapy combination at any time between cohort entry and index date.

\section{Potential confounders}

We adjusted the risk estimates for comorbid clinical conditions, measured before the index date, known to be associated with acute kidney injury, which could also influence the choice of antihypertensive and NSAID treatment. We thus adjusted all models for the indication for antihypertensive drug use (hypertension, heart failure, and coronary heart disease measured at cohort entry), rhythm disorders, valvular disease, diabetes, number of hospital admissions (any time before the index date), excessive alcohol use, smoking status, and body mass index (all based on the last measure before the index date). ${ }^{6}{ }^{22} 29-31$ To minimise the effect of severity of hypertension, we also adjusted the models for the blood pressure value recorded at cohort entry. We defined hypertension as "mild" when systolic or diastolic blood pressure was between 140 and $159 \mathrm{~mm} \mathrm{Hg}$ or 90 and 99 $\mathrm{mm} \mathrm{Hg}$, "moderate" when systolic or diastolic blood pressure was between 160 and $179 \mathrm{~mm} \mathrm{Hg}$ or 100 and $109 \mathrm{~mm} \mathrm{Hg}$, and "severe" when they were $180 \mathrm{~mm} \mathrm{Hg}$ or $110 \mathrm{~mm} \mathrm{Hg}$ or higher. ${ }^{16}$ Finally, we also adjusted the models for the use of other antihypertensive drugs ( $\alpha$ blockers, $\beta$ blockers, and calcium channel blockers), digoxin, clopidogrel, anti-arrhythmics, statins, antibiotics, immunosuppressive drugs, paracetamol, and corticosteroids, all measured in the year before the index date.

\section{Statistical analysis}

We estimated the overall incidence rate of acute kidney injury by dividing the total number of cases that occurred during the study period by the total person years of follow-up, with $95 \%$ confidence intervals based on the Poisson distribution. We used conditional logistic regression to compute odds ratios of acute kidney injury, which, for the time matched nested case-control method used here, provides unbiased estimates of the rate ratio and $95 \%$ confidence interval. ${ }^{32}$ In addition to age, sex, calendar year of cohort entry, prevalent user status, and duration of follow-up on which the logistic regression was conditioned, we adjusted for the confounders described above.

In the primary analysis, we compared current users of a double therapy combination, consisting of diuretics or angiotensin converting enzyme inhibitors or angiotensin receptor blockers with NSAIDs, with patients currently using these antihypertensive drugs but without NSAIDs. Likewise, we compared current users of a triple therapy combination, consisting of diuretics and angiotensin converting enzyme inhibitors or angiotensin receptor blockers with NSAIDs, with patients currently using these antihypertensive drugs without NSAIDs. We chose these reference groups to minimise confounding by indication. ${ }^{33}$

In secondary analyses, we assessed whether the risk of acute kidney injury associated with double and triple therapy combinations varied according to half life of NSAIDs and duration of use (that is, length of exposure to double or triple therapy combination). Thus, patients deemed to be current users of such combinations were further categorised according to whether they used NSAIDs with short half lives $(<12$ hours: aceclofenac, acemetacin, diclofenac, etodolac, fenbufen, fenoprofen, flurbiprofen, ibuprofen, indometacin, ketoprofen, mefenamic acid, tiaprofenic acid, aspirin) or long half lives ( $\geq 12$ hours: azaprazone, meloxicam, nabumetone, naproxen, piroxican, sulindac, tenoxicam), as well as according to duration of exposure ( $\leq 30,31-60,61-90,>90$ days). We assessed effect modification by half life of NSAID and duration of use of double and triple therapy combinations by including interaction terms between those categories and the relevant exposure groups.

We also did several sensitivity analyses to evaluate the robustness of the results. The first consisted of repeating all analyses by restricting the cases to the subset requiring dialysis. In a second analysis, we repeated the analyses by additionally matching cases and controls on general practice to further control for potential residual confounders from practice level prescribing patterns and social deprivation (we did not match on general practice as part of the primary analysis because of the exclusion of 573 (26\%) cases). In a third analysis, we verified whether the introduction in the UK of new quality outcome framework guidelines over the study period, concerning the recording and treatment of diabetes and chronic kidney disease,${ }^{345}$ had affected the accuracy of both diagnoses of acute kidney injury and chronic kidney failure in the CPRD. Thus, we stratified cases and matched controls on calendar period (1998-2002, 2003-07, 2008-10) and diabetes diagnosis (as these patients are prone to develop chronic and acute kidney diseases $\left.{ }^{36}{ }^{37}\right)$. In a fourth analysis, we tested the definition of current use by varying the width of the exposure time window and grace period to 60 and 30 days. In a fifth analysis, we stratified cases and matched controls on prevalent user status (this was a matching variable) to assess the effect of including prevalent users in the main models. In a sixth analysis, we assessed the impact of over the counter use of NSAIDs by restricting the cases and matched controls to patients with osteoarthritis, a population for whom the chronic use of NSAIDs is likely to involve physicians' prescriptions. Finally, because the CPRD does not include information on drug exposure in the inpatient setting, possibly leading to immeasurable time bias, ${ }^{38}$ we assessed the effect of this bias by repeating the analyses after excluding patients who had been admitted to hospital during the current time window. We used SAS version 9.2 for all analyses. 


\section{Results}

A cohort of 487372 patients using antihypertensive drugs met the study inclusion criteria (fig $1 \Downarrow$ ); they were followed for a mean of 5.9 (SD 3.4) years, generating 3047813 person years of follow-up. We identified 2215 cases of acute kidney injury during follow-up, yielding an overall incidence rate of 7/10 000 (95\% confidence interval 7/10 000 to $8 / 10000$ ) person years.

Table $1 \Downarrow$ shows the demographic and clinical characteristics of the cases and matched controls. Hypertension was the main indication for use of antihypertensive drugs among cases and controls. As expected, cases were likely to have a greater number of hospital admissions and more likely to have diabetes and other cardiovascular diseases. Furthermore, cases differed from controls in terms of use of anti-arrhythmics, digoxin, clopidogrel, statins, antibiotics, immunosuppressive drugs, paracetamol, and corticosteroids. Excessive alcohol use, overweight and underweight patients, and smokers were also proportionally more common among cases than controls.

Table $2 \Downarrow$ shows the results of the primary analysis. Overall, current use of a double therapy combination of a diuretic or an angiotensin converting enzyme inhibitor or angiotensin receptor blocker with NSAIDs was not associated with an increased rate of acute kidney injury. On the other hand, current use of a triple therapy combination was associated with a $31 \%$ higher rate of acute kidney injury (rate ratio $1.31,95 \%$ confidence interval 1.12 to 1.53$)$.

Table $3 \Downarrow$ shows the results of the secondary analyses. When we examined current users of a double therapy combination according to half life of NSAID and duration of use, none of the categories reached statistical significance. However, for the combination of diuretics with NSAIDs, we found an overall effect modification by duration of use, with the highest risk observed in the first 30 days of use, although that estimate did not reach statistical significance (rate ratio $1.46,0.96$ to 2.24).

The use of a triple therapy combination with NSAIDs with long half lives tended to be associated with a higher increased risk of acute kidney injury ( $\geq 12$ hours: rate ratio $1.77,1.07$ to 2.93 ) than with NSAIDs with shorter half-lives ( $<12$ hours: 1.29, 1.11 to 1.51 ), although the $\mathrm{P}$ value for interaction did not reach statistical significance (table $3 \Downarrow$ ). With respect to duration of use, an $82 \%$ (rate ratio 1.82, 1.35 to 2.46) increased risk of acute kidney injury was observed in the first 30 days of use, whereas the adjusted rate ratio progressively decreased with longer periods of use and was no longer significant after more than 90 days of use (1.01, 0.84 to 1.23 ; P for interaction< $<.001)$.

\section{Sensitivity analyses}

When we restricted the analyses to the 262 cases of acute kidney injury requiring dialysis, double and triple therapy combinations did not achieve statistical significance, although the rate ratio for triple therapy combination was numerically elevated (1.13, 0.69 to 1.77 ) compared with double therapy combinations (diuretics: $0.71,0.36$ to 1.43 ; angiotensin converting enzyme inhibitors or angiotensin receptor blockers: $0.69,0.36$ to 1.31 ). These analyses were limited by statistical power given the relatively few cases exposed to double $(n=36)$ and triple therapy $(n=57)$ combinations.

With cases and controls matched on general practice, the rate ratios did not achieve statistical significance. This was probably a result of exclusion of 573 cases for whom we could not find suitable controls. However, we found statistically significant associations in terms of half life of NSAID and duration of use, consistent with those in the main analyses (supplementary tables A1 and A2: see web extra).

When we stratified by calendar period, although we found a non-statistically significant association for the 1998-2002 time band, the results for the most recent time bands (2003-07 and 2008-10) were in line with those in the primary analysis (supplementary table B1). Furthermore, stratification of cases and matched controls on the presence of diabetes led to results consistent with those of the primary analysis, indicating that the results were unlikely to have been influenced by the accuracy of recording acute kidney injury and chronic kidney disease (supplementary table B2). We also varied the width of the exposure time windows and grace periods to 60 and 30 days. The point estimates were lower with the 60 and 30 day time windows, possibly owing to increased misclassifications of exposure, thus supporting the choice of a 90 day time window. Nevertheless, the directions of the risks were consistent with those observed with a 90 day time window (supplementary tables C1, C2, D1, and D2).

When we stratified the cases and matched controls by prevalent user status, the results were still consistent with those of the primary analysis; the triple therapy combination was associated with an increased risk of acute kidney injury in both prevalent and incident cases and controls. However, the rate ratios were higher for the new users than for the prevalent users, showing an underestimation of the effect when prevalent users were included in the overall cohort (supplementary tables E1, E2, F1, and F2). ${ }^{39}$ With stratification by the presence of osteoarthritis, a population for whom NSAIDs would normally be prescribed, although the triple therapy combination did not achieve statistical significance, probably owing to the fewer exposed cases $(n=126)$, the point estimates were comparable to those for patients without osteoarthritis, indicating that over the counter use of NSAIDs is unlikely to have caused important misclassifications of exposure (supplementary table G).

Finally, to account for immeasurable time bias, ${ }^{38}$ we restricted the analysis to those cases and controls who were not admitted to hospital during the current time window. The results of this sensitivity analysis were consistent with those of the primary analysis for both double (diuretics: rate ratio $1.08,0.81$ to 1.44 ; angiotensin converting enzyme inhibitors or angiotensin receptor blockers: $0.92,0.67$ to 1.27$)$ and triple $(1.33,1.09$ to 1.61$)$ therapy combinations.

\section{Discussion}

To our knowledge, this is the first large population based study of patients (almost 500 000) using antihypertensive drugs to have investigated the association between the use of different combinations of antihypertensive drugs (diuretics, angiotensin converting enzyme inhibitors, and angiotensin receptor blockers) with non-steroidal anti-inflammatory drugs on the risk of acute kidney injury. Our results indicate that the use of a double therapy combination is not associated with an increased risk of acute kidney injury, although the risk was modified by the duration of use of a diuretic-NSAID combination. On the other hand, the use of a triple therapy combination was associated with an overall $31 \%$ higher risk, which is driven by a nearly twofold increased risk in the first 30 days of use. Overall, these results remained consistent after several sensitivity analyses.

\section{Comparisons with previous studies}

The known risks associated with these double and triple therapy combinations are currently based on pharmacovigilance case series and a few epidemiological studies. ${ }^{1729} 3040$ These studies 
had several methodological shortcomings. The only study that specifically investigated the risk of acute kidney injury due to these double or triple therapy combinations was probably subject to confounding by indication and severity (heart failure can itself lead to acute kidney injury). ${ }^{17}{ }^{33} 41-43$ On the other hand, in the others studies, ${ }^{29}{ }^{30}$ the primary focus was on the association between NSAIDs and acute kidney injury, and interaction with diuretics or angiotensin converting enzyme

inhibitors/angiotensin receptor blockers and NSAIDs was a secondary outcome. These studies were not adequately powered to investigate the association between double and triple therapy combinations and the risk of acute kidney injury. ${ }^{29} 30$

In one cross sectional study of 301 patients, ${ }^{17}$ the use of two or more drugs among diuretics, angiotensin converting enzyme inhibitors, and angiotensin receptor blockers with NSAIDs was associated with an increased risk of renal impairment, compared with non-use. However, the authors adopted mean values of blood creatinine concentrations as the study outcome, without using a specific cut-off ( such as creatinine concentration $>0.20$ $\mathrm{mmol} / \mathrm{L}$ ) to define acute kidney injury. Thus, their outcome was not specific to identify acute kidney injury and also included subclinical renal impairments. Moreover, they were unable to adjust for potential confounders such as heart failure. The increased risk observed may thus have been partly affected by confounding by indication and severity. ${ }^{33}$ 41-43

In a nested case-control study, Huerta and et al reported an increased risk of acute kidney injury due to diuretic-NSAIDs interaction, estimated through the synergy index $(S=2.4,95 \%$ confidence interval 0.2 to 2.4 ) ${ }^{29}$ This measurement, as well as the relative excessive risk due to interaction index (RERI), quantifies the risk due to drug-drug interactions on an additive scale for dichotomous factors. $\mathrm{S}>1$ and RERI $>0$ indicate increased risk when two or more drugs are combined versus monotherapy. ${ }^{44}$ However, that study was underpowered to report a firm conclusion about its results. ${ }^{29}$ In another study, Lafrance et al confirmed an interaction between the use of diuretics and NSAIDs (RERI $=0.38,95 \%$ confidence interval 0.25 to 0.51 ).$^{30}$ However, neither of these two studies found an interaction between angiotensin converting enzyme inhibitors or angiotensin receptor blockers and NSAIDs. No previous investigations have assessed whether a duration-response relation existed for the use of double and triple therapy combinations and the risk of acute kidney injury. In this study, we specifically focused our investigation on these double and triple therapy combinations. Furthermore, we did a nested case-control analysis within a cohort of antihypertensive drug users and adjusted for their indications, thus minimising the effect of these confounders. ${ }^{41-43}$ Additionally, we adjusted the models for the blood pressure values recorded at cohort entry, thus minimising the effect of severity of hypertension. We were also able to examine the duration-response relation for both double and triple therapy combinations.

\section{Biological mechanisms}

An interesting finding of this study is an overall increased risk of acute kidney injury with a triple therapy combination but no overall increased risk with a double therapy combination. Among patients on a combination of diuretics and NSAIDs (without an angiotensin converting enzyme inhibitors or angiotensin receptor blockers), despite a reduction in renal blood flow and the presence of renal afferent arteriolar constriction, glomerular filtration is probably maintained as a result of the effect of angiotensin II mediated efferent arteriolar vasoconstriction and sodium retention. As observed in this study, only patients exposed to diuretics and NSAIDs early in the course of treatment may be more prone to develop acute kidney injury. This result is biologically consistent with the potential effect of a drastic hypovolaemia exerted by diuretics, which is further exacerbated by the vasoconstrictive effect of NSAIDs. ${ }^{71}{ }^{21}$ On the other hand, among patients taking angiotensin converting enzyme inhibitors or angiotensin receptor blockers and NSAIDs (without a diuretic), the afferent vasoconstrictive stimulus induced by the NSAIDs through inhibition of prostacyclins synthesis is probably insufficient to substantially increase the risk of acute kidney injury in the presence of a normal extracellular fluid volume and preserved renal blood flow. ${ }^{721} 31$

In contrast, among users of the triple therapy combination, the decreased inflow to the glomerulus resulting from the diuretic and NSAID cannot be compensated owing to blockade of the renin-angiotensin system, resulting in an increased risk of acute kidney injury. Although we did not find an effect modification by half life of NSAID, patients using NSAIDs with longer half lives have a more pronounced risk of acute kidney injury. ${ }^{29}$ Thus, the higher point estimates observed with NSAIDs with long half lives is suggestive of a more sustained constriction of the afferent arteriole. ${ }^{721}$ When we considered the duration of exposure to a triple therapy combination, the highest risk of acute kidney injury was in the first 30 days of use. Although the basis of this is still unclear, it might be explained by an early and severe deteriorating effect of NSAIDs in susceptible patients,${ }^{45}$ who are heavily dependent on prostacyclins to maintain renal function. ${ }^{71}$ Furthermore, patients may initially use a greater number of NSAID pills early on than later, as some causes of pain may abate over time.

\section{Strengths and limitations}

This study has several strengths. Firstly, we used the Clinical Practice Research Datalink, which is a large primary care database containing longitudinal data on patients' medical history, lifestyle (smoking, alcohol use, and body mass index measurements), and indication for use of antihypertensive drugs. Thus, we were able to adjust for several important potential confounders. Secondly, both exposure and covariate definitions were time dependent as a result of the risk set sampling method used to select controls. Thirdly, exposure in the CPRD is prospectively collected, eliminating the possibility of recall bias. Finally, we did several sensitivity analyses, which, overall, produced results consistent with those of the primary analysis. This study has some potential limitations. Firstly, the identification of acute kidney injury may have been subject to some misclassification. However, our overall incidence rate of acute kidney injury is higher than what has been reported in the general population, ${ }^{1}$ which is expected in a cohort of antihypertensive drugs users. ${ }^{22}$ In addition, we identified acute kidney injury events by using hospital admission data (diagnosis in primary position; those reporting hospital admission for acute kidney injury in secondary diagnosis position, or dialysis related procedures that were not followed (within 30 days) by a diagnosis of acute kidney injury in primary position, were censored), ${ }^{46}$ whose validity has been demonstrated in the more clinically severe subgroup requiring dialysis (sensitivity $90 \%$; positive predictive value $94 \%$ ). ${ }^{26}{ }^{27}$ When we restricted the analysis to this more severe subgroup, we observed a lower point estimate for the triple therapy combination $(1.13 v 1.31)$, although the upper bound of the confidence interval does not rule out a possible increased risk (rate ratio 1.77). Although this shift in the rate ratio may be simply due to instability of the point estimate because of the fewer exposed cases on which the analysis was based $(n=57)$, confounding by contraindication is 
also possible (that is, physicians refrained from prescribing NSAIDs to patients at a higher risk of developing acute kidney injury requiring dialysis), ${ }^{48}$ which could have biased the rate ratios towards the null.

Secondly, because of the observational nature of this study, residual confounding by indication and disease severity may be present. However, we specifically dealt with this possibility by using active treatment comparators (for example, combination of diuretic and NSAID versus diuretic only). Therefore, assuming that residual confounding from unmeasured variables was non-differential between exposure groups is reasonable. Furthermore, adjusting the models for severity of hypertension had little effect on the adjusted rate ratios, indicating that this variable was probably well balanced between groups. Moreover, we observed similar results when we stratified for diabetes, as well as in terms of half life of NSAID and duration of use when we additionally matched cases and controls on general practice, in an attempt to further control for practice specific prescribing patterns and social deprivation. Reassuringly, the fact that we observed a duration-response relation and the point estimates were consistently lower with a shorter (60 and 30 days) exposure time window and grace period (that is, the likelihood of being concurrently exposed to antihypertensive drugs and NSAIDs was reduced) indicates that residual confounding was probably minimal.

Thirdly, we were unable to control for exposure to contrast media injected during in-hospital cardiovascular examinations (such as angiography) or for other nephrotoxins (such as aminoglycoside antibiotics) that might have contributed to the risk of acute kidney injury. ${ }^{49}$ However, when we controlled for immeasurable time bias by excluding patients admitted to hospital in the current time window, ${ }^{38}$ the results remained consistent with those of the primary analysis, showing that previous in-hospital exposure to other nephrotoxins as well as in-hospital exposures to double or triple therapy combinations were unlikely to have influenced the observed associations.

Finally, whereas antihypertensive drugs are probably well captured in the CPRD, some misclassification of exposure with some NSAIDs that are available over the counter is possible. Such misclassifications of exposure would have diluted the association towards the null, so the increased risks observed in this study may have been partly underestimated. ${ }^{50}$ However, we obtained consistent results when we restricted the analyses to those patients treated for osteoarthritis, a population more likely to be exposed to NSAIDs by prescription. Nevertheless, given that over the counter drug information is generally unavailable in claims databases, other data sources with such information are needed to better quantify the risk of acute kidney injury accounting for the over the counter use of NSAIDs.

\section{Conclusions and policy implications}

Acute kidney injury is a major public health concern, which has been associated with a mortality rate exceeding $50 \%$. $^{2-6} 5152$ Although the prevalence of cardiovascular diseases has been on the rise in Western countries, the proper use of antihypertensive drugs has been shown to have a favourable effect in preventing major cardiovascular events. ${ }^{1628534}$ However, the use of such therapies might be concurrent with chronic (for example, arthritis) and acute (for example, flu and flu-like syndromes) inflammatory diseases that require anti-inflammatory or analgesic drug treatment. Given that NSAIDs are widely used (40-60\% as lifetime prevalence in the general population ${ }^{29}{ }^{30}$ ) and that a greater incidence rate of acute kidney injury was estimated among antihypertensive drugs users than in the general population, increased vigilance may be warranted when diuretics and angiotensin converting enzyme inhibitors or angiotensin receptor blockers are used concurrently with NSAIDs. ${ }^{20} 55$ In particular, major attention should be paid early in the course of treatment, and a more appropriate use and choice among the available anti-inflammatory or analgesic drugs could therefore be applied in clinical practice.

Contributors: All authors participated in the study design. SS acquired the data. FL, LA, and HY did the statistical analyses. FL wrote the initial draft, and all authors critically revised the manuscript. SS is the guarantor.

Funding: This study was funded in part by infrastructure grants from the Drug Safety and Effectiveness Network (DSEN), the Canadian Institute of Health Research (CIHR), and the Canada Foundation for Innovation. The funding sources had no role in the design, analysis, or interpretation of the results, and thus the authors were independent from the funding sources. FL is the recipient of an LDI post-doctoral research award, LA is the recipient of a Chercheur-Boursier career award from the Fonds de recherche en santé du Québec, and SS is the recipient of the James McGill chair award.

Competing interests: All authors have completed the ICMJE uniform disclosure form at www.icmje.org/coi_disclosure.pdf (available on request from the corresponding author) and declare: database acquisitions were funded by the Canadian Institute of Health Research (CIHR) and the Canada Foundation for Innovation; SS has received research grants and participated in advisory board meetings and/or as a speaker at conferences for AstraZeneca, Boehringer-Ingelheim, GlaxoSmithKline, Novartis, Pfizer, and Merck; SJN has received speakers' honorariums from Baxter Healthcare and Merck Frosst; no other relationships or activities that could appear to have influenced the submitted work.

Ethical approval: The study protocol was approved by the Independent Scientific Advisory Committee of the Clinical Practice Research Datalink and by the Research Ethics Committee of the Jewish General Hospital, Montreal, Canada.

Data sharing: No additional data available.

1 World Health Organization (Europe). Databases. www.euro.who.int/en/what-we-do/dataand-evidence/databases.

2 Lo LJ, Go AS, Chertow GM, McCulloch CE, Fan D, Ordonez JD, et al. Dialysis-requiring acute renal failure increases the risk of progressive chronic kidney disease. Kidney Int 2009;76:893-9.

3 Hsu CY, McCulloch CE, Fan D, Ordonez JD, Chertow GM, Go AS. Community-based incidence of acute renal failure. Kidney Int 2007;72:208-12.

4 Hsu CY, Chertow GM, McCulloch CE, Fan D, Ordonez JD, Go AS. Nonrecovery of kidney function and death after acute on chronic renal failure. Clin J Am Soc Nephrol 2009;4:891-8.

5 Liangos O, Wald R, O'Bell JW, Price L, Pereira BJ, Jaber BL. Epidemiology and outcomes of acute renal failure in hospitalized patients: a national survey. Clin J Am Soc Nephrol 2006;1:43-51.

6 Kellum JA, Angus DC. Patients are dying of acute renal failure. Crit Care Med 2002;30:2156-7.

7 Schetz M, Dasta J, Goldstein S, Golper T. Drug-induced acute kidney injury. Curr Opin Crit Care 2005;11:555-65.

8 Wu TY, Jen MH, Bottle A, Molokhia M, Aylin P, Bell D, et al. Ten-year trends in hospital admissions for adverse drug reactions in England 1999-2009. J R Soc Med 2010:103:239-50.

9 Smets HL, De Haes JF, De Swaef A, Jorens PG, Verpooten GA. Exposure of the elderly to potential nephrotoxic drug combinations in Belgium. Pharmacoepidemiol Drug Saf 2008;17:1014-9.

10 Knauf H, Bailey MA, Hasenfuss G, Mutschler E. The influence of cardiovascular and antiinflammatory drugs on thiazide-induced hemodynamic and saluretic effects. Eur $J$ Clin Pharmacol 2006;62:885-92.

11 Thurman JM, Parikh CR. Peeking into the black box: new biomarkers for acute kidney injury. Kidney Int 2008;73:379-81.

12 Ishiguro C, Fujita T, Omori T, Fujii Y, Mayama T, Sato T. Assessing the effects of non-steroidal anti-inflammatory drugs on antihypertensive drug therapy using post-marketing surveillance database. J Epidemiol 2008:18:119-24.

13 Hernandez-Diaz S, Garcia-Rodriguez LA. Epidemiologic assessment of the safety of conventional nonsteroidal anti-inflammatory drugs. Am J Med 2001;110(suppl 3A):20-7S

14 Chobanian AV, Bakris GL, Black HR, Cushman WC, Green LA, Izzo JL Jr, et al. Seventh report of the Joint National Committee on Prevention, Detection, Evaluation, and Treatment of High Blood Pressure. Hypertension 2003;42:1206-52.

15 Chobanian AV, Bakris GL, Black HR, Cushman WC, Green LA, Izzo JL Jr, et al. The Chenth Report of the Joint National Committee on Prevention, Detection, Evaluation, and Treatment of High Blood Pressure: the JNC 7 report. JAMA 2003;289:2560-72. 


\section{What is already known about this topic}

Acute kidney injury is a major drug related concern

The combination of one or two antihypertensive drugs (angiotensin converting enzyme (ACE) inhibitors, angiotensin receptor blockers (ARBs) and diuretics) with non-steroidal anti-inflammatory drugs (NSAIDs) can theoretically increase the risk of acute kidney injury

Little is known about the risk of acute kidney injury associated with the use of these double or triple therapy combinations in practice

\section{What this paper adds}

Double therapy combinations consisting of addition of NSAIDs to diuretics, ACE inhibitors, or ARBs did not generally increase the risk of acute kidney injury

A triple therapy combination consisting of addition of NSAIDs to diuretics and ACE inhibitors or ARBs was associated with an increased risk of acute kidney injury

The risk of acute kidney injury with triple therapy was particularly elevated during the first 30 days of use

16 Mancia G, Laurent S, Agabiti-Rosei E, Ambrosioni E, Burnier M, Caulfield MJ, et al. Reappraisal of European guidelines on hypertension management: a European Society of Hypertension Task Force document. Blood Press 2009;18:308-47.

17 Loboz KK, Shenfield GM. Drug combinations and impaired renal function-the 'triple whammy'. Br J Clin Pharmacol 2005;59:239-43.

18 Mathew TH. Drug-induced renal disease. Med J Aust 1992;156:724-8.

19 Thomas MC. Diuretics, ACE inhibitors and NSAIDs-the triple whammy. Med J Aust 2000;172:184-5.

20 Baraldi A, Ballestri M, Rapana R, Lucchi L, Borella P, Leonelli M, et al. Acute renal failure of medical type in an elderly population. Nephrol Dial Transplant 1998;13(suppl 7):25-9.

21 Greger R. Physiology of renal sodium transport. Am J Med Sci 2000;319:51-62.

22 Kellum J, Leblanc M, Venkataraman R. Acute renal failure. Am Fam Physician 2007;76:418-22

23 Garcia Rodriguez LA, Perez Gutthann S. Use of the UK General Practice Research Database for pharmacoepidemiology. Br J Clin Pharmacol 1998;45:419-25.

24 Herrett E, Thomas SL, Schoonen WM, Smeeth L, Hall AJ. Validation and validity of diagnoses in the General Practice Research Database: a systematic review. Br J Clin Pharmacol 2010;69:4-14.

25 Khan NF, Harrison SE, Rose PW. Validity of diagnostic coding within the General Practice Research Database: a systematic review. Br J Gen Pract 2010;60:e128-36.

26 Vlasschaert ME, Bejaimal SA, Hackam DG, Quinn R, Cuerden MS, Oliver MJ, et al. Validity of administrative database coding for kidney disease: a systematic review. Am J Kidney Dis 2011;57:29-43.

27 Waikar SS, Wald R, Chertow GM, Curhan GC, Winkelmayer WC, Liangos O, et al. Validity of international classification of diseases, ninth revision, clinical modification codes for acute renal failure. J Am Soc Nephrol 2006:17:1688-94.

28 Mazzaglia G, Ambrosioni E, Alacqua M, Filippi A, Sessa E, Immordino V, et al. Adherence to antihypertensive medications and cardiovascular morbidity among newly diagnosed hypertensive patients. Circulation 2009;120:1598-605

29 Huerta C, Castellsague J, Varas-Lorenzo C, Garcia Rodriguez LA. Nonsteroidal anti-inflammatory drugs and risk of ARF in the general population. Am J Kidney Dis 2005;45:531-9.

30 Lafrance JP, Miller DR. Selective and non-selective non-steroidal anti-inflammatory drugs and the risk of acute kidney injury. Pharmacoepidemiol Drug Saf 2009;18:923-31

31 Taber SS, Pasko DA. The epidemiology of drug-induced disorders: the kidney. Expert Opin Drug Saf 2008;7:679-90.

32 Breslow NE. Statistics in epidemiology: the case-control study. J Am Stat Assoc 1996:91:14-28.

33 Salas M, Hofman A, Stricker BH. Confounding by indication: an example of variation in the use of epidemiologic terminology. Am J Epidemiol 1999;149:981-3.

34 NHS Information Centre for Health and Social Care. QOF 2009-10 data tables. 2012. www.ic.nhs.uk/statistics-and-data-collections/supporting-information/audits-andperformance/the-quality-and-outcomes-framework/qof-2009-10/data-tables.

35 Kerr M, Bray B, Medcalf J, O'Donoghue DJ, Matthews B. Estimating the financial cost of chronic kidney disease to the NHS in England. Nephrol Dial Transplant 2012;27(suppl 3):iii73-80.

36 Remuzzi G, Schieppati A, Ruggenenti P. Clinical practice: nephropathy in patients with type 2 diabetes. N Engl J Med 2002;346:1145-51.

37 Girman CJ, Kou TD, Brodovicz K, Alexander CM, O'Neill EA, Engel S, et al. Risk of acute renal failure in patients with type 2 diabetes mellitus. Diabet Med 2012;29:614-21.

38 Suissa S. Immeasurable time bias in observational studies of drug effects on mortality. Am J Epidemiol 2008;168:329-35.

39 Ray WA. Evaluating medication effects outside of clinical trials: new-user designs. Am J Epidemiol 2003;158:915-20.

40 Adhiyaman V, Asghar M, Oke A, White AD, Shah IU. Nephrotoxicity in the elderly due to co-prescription of angiotensin converting enzyme inhibitors and nonsteroidal anti-inflammatory drugs. J R Soc Med 2001;94:512-4.
41 Han L, Kim N, Brandt C, Allore HG. Antidepressant use and cognitive deficits in older men: addressing confounding by indications with different methods. Ann Epidemiol 2012;22:9-16.

42 Psaty BM, Siscovick DS. Minimizing bias due to confounding by indication in comparative effectiveness research: the importance of restriction. JAMA 2010;304:897-8.

43 Quartey G, Feudjo-Tepie M, Wang J, Kim J. Opportunities for minimization of confounding in observational research. Pharm Stat 2011;10:539-47.

44 Knol MJ, VanderWeele TJ, Groenwold RH, Klungel OH, Rovers MM, Grobbee DE. Estimating measures of interaction on an additive scale for preventive exposures. Eur $J$ Epidemiol 2011;26:433-8.

45 Suissa S, Garbe E. Primer: administrative health databases in observational studies of drug effects-advantages and disadvantages. Nat Clin Pract Rheumatol 2007;3:725-32.

46 Perez Gutthann S, Garcia Rodriguez LA, Raiford DS, Duque Oliart A, Ris Romeu J. Nonsteroidal anti-inflammatory drugs and the risk of hospitalisation for acute renal failure. Arch Intern Med 1996;156:2433-9.

47 Schneider V, Levesque LE, Zhang B, Hutchinson T, Brophy JM. Association of selective and conventional nonsteroidal antiinflammatory drugs with acute renal failure: a population-based, nested case-control analysis. Am J Epidemiol 2006;164:881-9.

48 Feenstra H, Grobbee RE, in't Veld BA, Stricker BH. Confounding by contraindication in a nationwide cohort study of risk for death in patients taking ibopamine. Ann Intern Med 2001:134:569-72.

49 Morabito S, Pistolesi V, Benedetti G, Di Roma A, Colantonio R, Mancone M, et al. Incidence of contrast-induced acute kidney injury associated with diagnostic or interventional coronary angiography. J Nephrol 2012:25:1098-107.

50 Yood MU, Campbell UB, Rothman KJ, Jick SS, Lang J, Wells KE, et al. Using prescription claims data for drugs available over-the-counter (OTC). Pharmacoepidemiol Drug Saf 2007;16:961-8.

51 Nash K, Hafeez A, Hou S. Hospital-acquired renal insufficiency. Am J Kidney Dis 2002;39:930-6.

52 Shusterman N, Strom BL, Murray TG, Morrison G, West SL, Maislin G. Risk factors and outcome of hospital-acquired acute renal failure: clinical epidemiologic study. Am J Med 1987;83:65-71.

53 Olsen MH, Mallion JM, Rahn KH, Erdine S, Viigimaa M, Laurent S, et al. Agreement within Europe about antihypertensive treatment and education-results from the European Society of Hypertension questionnaire. J Hypertens 2010;28:1593-4.

54 Gislason GH, Rasmussen JN, Abildstrom SZ, Schramm TK, Hansen ML, Buch P, et al. Persistent use of evidence-based pharmacotherapy in heart failure is associated with improved outcomes. Circulation 2007;116:737-44.

55 LaMarr B, Valdez C, Driscoll K, Ryan M. Influence of pharmacist intervention on prescribing of angiotensin-converting-enzyme inhibitors, angiotensin II-receptor blockers, and aspirin for diabetic patients. Am J Health Syst Pharm 2010;67:290-4.

56 LaCivita C, Funkhouser E, Miller MJ, Ray MN, Saag KG, Kiefe Cl, et al. Patient-reported communications with pharmacy staff at community pharmacies: the Alabama NSAID Patient Safety Study, 2005-2007. J Am Pharm Assoc (2003) 2009;49:e110-7.

Accepted: 10 December 2012

\section{Cite this as: BMJ 2013;346:e8525}

This is an open-access article distributed under the terms of the Creative Commons Attribution Non-commercial License, which permits use, distribution, and reproduction in any medium, provided the original work is properly cited, the use is non commercial and is otherwise in compliance with the license. See: http://creativecommons.org/licenses/by$\mathrm{nc} / 2.0 /$ and http://creativecommons.org/licenses/by-nc/2.0/legalcode. 


\section{Tables}

Table 1/ Characteristics of acute kidney injury cases and matched controls. Values are numbers (percentages) unless stated otherwise Characteristics Cases $(n=2215)$ Controls $(n=21993)$

Mean (SD) age (years) ${ }^{\star}$

$76.9(10.9) \quad 76.9(10.7)$

Male sex*

$1133(51.2) \quad 11226(51.0)$

Mean (SD) duration of follow-up (years) ${ }^{*}$

$5.9(3.4) \quad 5.9(3.4)$

Body mass index:

\begin{tabular}{lcc}
\hline$<18.5$ & $48(2.2)$ & $346(1.6)$ \\
\hline $18.5-24$ & $423(19.1)$ & $4662(21.2)$ \\
\hline $25-29$ & $468(21.1)$ & $5563(25.3)$ \\
\hline$\geq 30$ & $467(21.1)$ & $3548(16.1)$ \\
\hline Unknown & $809(36.5)$ & $7874(35.8)$ \\
\hline Excessive alcohol use & $302(13.6)$ & $1882(8.6)$ \\
\hline Smoking status: & &
\end{tabular}

\begin{tabular}{lll} 
Ever & $1288(58.1)$ & $11207(51.0)$ \\
\hline
\end{tabular}

\begin{tabular}{lcc}
\hline Never & $848(38.3)$ & $9962(45.3)$ \\
\hline Unknown & $79(3.6)$ & $824(3.7)$
\end{tabular}

\begin{tabular}{lcc} 
At least one hospital admission† & $79(3.6)$ & $824(3.7)$ \\
\hline
\end{tabular}

Mean (SD) No of hospital admissionsł $6.3(6.1) \quad 2.9(4.3)$

\begin{tabular}{lll}
\hline Diabetes & $726(32.8)$ & $3905(17.8)$
\end{tabular}

Indication for use:

\begin{tabular}{|c|c|c|}
\hline Hypertension & $1145(51.7)$ & $12684(57.7)$ \\
\hline Congestive heart failure & $130(5.9)$ & $512(2.3)$ \\
\hline Coronary artery disease & $37(1.7)$ & $339(1.5)$ \\
\hline Two or more & $155(7.0)$ & $782(3.6)$ \\
\hline Unknown & $748(33.8)$ & $7676(34.9)$ \\
\hline Rhythm disorders & $456(20.6)$ & $2728(12.4)$ \\
\hline Valvular disease & $5(0.2)$ & $28(0.1)$ \\
\hline Other cardiovascular disease & $17(0.8)$ & $44(0.2)$ \\
\hline \multicolumn{3}{|l|}{ Blood pressure $(\mathrm{mm} \mathrm{Hg})$ : } \\
\hline $140 \leq$ systolic $<160$ or $90 \leq$ diastolic $<100$ & $751(33.9)$ & $7705(35.0)$ \\
\hline $160 \leq$ systolic $<180$ or $100 \leq$ diastolic $<110$ & $318(14.4)$ & $2924(13.3)$ \\
\hline Systolic $\geq 180$ or diastolic $\geq 110$ & $114(5.1)$ & $805(3.7)$ \\
\hline Unknown & $1032(46.6)$ & $10559(48.0)$ \\
\hline \multicolumn{3}{|l|}{ Other antihypertensive drugs: } \\
\hline Calcium channel blockers & $712(32.1)$ & $7340(33.4)$ \\
\hline$\beta$ blockers & $701(31.7)$ & $6366(29.0)$ \\
\hline Anti-arrhythmics & $199(9.0)$ & $1515(6.9)$ \\
\hline Digoxin & $304(13.7)$ & $1407(6.4)$ \\
\hline Clopidogrel & $150(6.8)$ & $921(4.2)$ \\
\hline Statins & 1039 (46.9) & $8951(40.7)$ \\
\hline Antibiotics & $1448(65.4)$ & 9291 (42.2) \\
\hline Immunosuppressive agents & $123(5.6)$ & 509 (2.3) \\
\hline Paracetamol & 1234 (55.7) & $8905(40.5)$ \\
\hline Corticosteroids & 427 (19.3) & 2993 (13.6) \\
\hline
\end{tabular}

*Matching variables (along with year of cohort entry).

†Within current time window before index date.

¥From Hospital Episode Statistics database. 
Table 2| Rate ratio of acute kidney injury associated with exposure to current double or triple therapy combination. Values are numbers (percentages) unless stated otherwise

\begin{tabular}{|c|c|c|c|c|}
\hline \multirow[b]{2}{*}{ Current use* } & \multirow[b]{2}{*}{ Cases $(n=2215)$} & \multirow[b]{2}{*}{ Controls (n=21 993) } & \multicolumn{2}{|c|}{ Rate ratio $(95 \% \mathrm{Cl})$} \\
\hline & & & Crude & Adjusted† \\
\hline Diuretics only & $209(9.4)$ & $2632(12.0)$ & Reference & Reference \\
\hline Diuretics plus NSAIDs & $156(7.0)$ & $1739(7.9)$ & $1.16(0.93$ to 1.44$)$ & $1.02(0.81$ to 1.28$)$ \\
\hline $\begin{array}{l}\text { ACE inhibitors or angiotensin receptor } \\
\text { blockers only }\end{array}$ & $148(6.7)$ & $1889(8.6)$ & Reference & Reference \\
\hline $\begin{array}{l}\text { ACE inhibitors or angiotensin receptor } \\
\text { blockers plus NSAIDs }\end{array}$ & $138(6.2)$ & $1907(8.7)$ & 0.96 (0.75 to 1.22$)$ & 0.89 (0.69 to 1.15$)$ \\
\hline $\begin{array}{l}\text { Diuretics plus ACE inhibitors or angiotensin } \\
\text { receptor blockers }\end{array}$ & $414(18.7)$ & $2432(11.1)$ & Reference & Reference \\
\hline $\begin{array}{l}\text { Diuretics plus ACE inhibitors or angiotensin } \\
\text { receptor blockers plus NSAIDs }\end{array}$ & $544(24.6)$ & $2424(11.0)$ & $1.34(1.17$ to 1.54$)$ & $1.31(1.12$ to 1.53$)$ \\
\hline
\end{tabular}

ACE=angiotensin converting enzyme; NSAID=non-steroidal anti-inflammatory drug.

*Within 90 days before index date; current users of other antihypertensive drugs and past users (>90 days before index date) of double and triple therapy combinations are not shown but were considered in regression model.

†Adjusted for covariates listed in table 1. 
Table 3| Rate ratio of acute kidney injury associated with exposure to current double or triple therapy combination according to half life of NSAID and duration of use. Values are numbers (percentages) unless stated otherwise

\begin{tabular}{|c|c|c|c|c|c|}
\hline \multirow[b]{2}{*}{ Current use* } & \multirow[b]{2}{*}{ Cases $(n=2215)$} & \multirow[b]{2}{*}{ Controls ( $n=21$ 993) } & \multicolumn{2}{|c|}{ Rate ratio $(95 \% \mathrm{Cl})$} & \multirow{2}{*}{$\begin{array}{c}\mathbf{P} \text { for } \\
\text { interaction }\end{array}$} \\
\hline & & & Crude & Adjusted $†$ & \\
\hline Diuretics only & $209(9.4)$ & $2632(12.0)$ & Reference & Reference & \\
\hline \multicolumn{6}{|l|}{ Diuretics plus NSAIDs: } \\
\hline NSAID's half life $<12$ hours & $151(6.8)$ & $1656(7.5)$ & $1.18(0.95$ to 1.47$)$ & $1.03(0.82$ to 1.30$)$ & \multirow[t]{2}{*}{0.5209} \\
\hline NSAID's half life $\geq 12$ hours & $5(0.2)$ & $83(0.4)$ & $0.74(0.30$ to 1.85$)$ & $0.76(0.30$ to 1.91$)$ & \\
\hline Duration $\ddagger \leq 30$ days & $32(1.4)$ & $208(1.0)$ & 1.87 (1.25 to 2.79$)$ & $1.46(0.96$ to 2.24$)$ & \multirow[t]{4}{*}{0.0211} \\
\hline Duration $\ddagger 31-60$ days & $26(1.2)$ & $246(1.1)$ & $1.32(0.86$ to 2.04$)$ & $1.12(0.71$ to 1.76$)$ & \\
\hline Duration $\ddagger 61-90$ days & $36(1.6)$ & $379(1.7)$ & $1.20(0.83$ to 1.74$)$ & $1.04(0.71$ to 1.53$)$ & \\
\hline Duration $\ddagger>90$ days & $62(2.8)$ & $906(4.1)$ & $0.90(0.67$ to 1.21$)$ & $0.83(0.61$ to 1.13$)$ & \\
\hline $\begin{array}{l}\text { ACE inhibitors or angiotensin receptor } \\
\text { blockers only }\end{array}$ & $148(6.7)$ & $1889(8.6)$ & Reference & Reference & \\
\hline \multicolumn{6}{|l|}{$\begin{array}{l}\text { ACE inhibitors or angiotensin receptor } \\
\text { blockers plus NSAIDs: }\end{array}$} \\
\hline NSAID's half life $<12$ hours & $132(6.0)$ & $1853(8.4)$ & $0.95(0.74$ to 1.21$)$ & $0.88(0.68$ to 1.14$)$ & \multirow[t]{2}{*}{0.7200} \\
\hline NSAID's half life $\geq 12$ hours & $6(0.3)$ & $54(0.3)$ & $1.43(0.60$ to 3.40$)$ & $1.04(0.41$ to 2.64$)$ & \\
\hline Duration $\ddagger \leq 30$ days & $17(0.8)$ & $195(0.9)$ & $1.13(0.67$ to 1.91$)$ & $1.13(0.66$ to 1.96$)$ & \multirow[t]{4}{*}{0.1149} \\
\hline Duration $\ddagger 31-60$ days & $24(1.1)$ & $247(1.1)$ & $1.26(0.80$ to 1.98$)$ & 1.07 (0.66 to 1.73$)$ & \\
\hline Duration $\ddagger 61-90$ days & $30(1.4)$ & $390(1.8)$ & $1.02(0.68$ to 1.54$)$ & 0.93 (0.61 to 1.43$)$ & \\
\hline Duration $\ddagger>90$ days & $67(3.0)$ & $1075(4.9)$ & $0.83(0.62$ to 1.13$)$ & $0.77(0.56$ to 1.06$)$ & \\
\hline $\begin{array}{l}\text { Diuretics plus ACE inhibitors or } \\
\text { angiotensin receptor blockers }\end{array}$ & $414(18.7)$ & $2432(11.1)$ & Reference & Reference & \\
\hline \multicolumn{6}{|l|}{$\begin{array}{l}\text { Diuretics plus ACE inhibitors or } \\
\text { angiotensin receptor blockers plus } \\
\text { NSAIDs: }\end{array}$} \\
\hline NSAID's half life $<12$ hours & $520(23.5)$ & $2343(10.7)$ & $1.33(1.15$ to 1.53$)$ & $1.29(1.11$ to 1.51$)$ & \multirow[t]{2}{*}{0.2157} \\
\hline NSAID's half life $\geq 12$ hours & $24(1.1)$ & $81(0.4)$ & 1.73 (1.08 to 2.77$)$ & 1.77 (1.07 to 2.93$)$ & \\
\hline Duration $\ddagger \leq 30$ days & $83(3.8)$ & $234(1.1)$ & 2.00 (1.52 to, 2.63$)$ & 1.82 (1.35 to 2.46$)$ & \multirow[t]{4}{*}{$<.0001$} \\
\hline Duration $\ddagger 31-60$ days & $94(4.2)$ & $309(1.4)$ & $1.76(1.37$ to 2.27$)$ & $1.63(1.24$ to 2.15$)$ & \\
\hline Duration $\ddagger 61-90$ days & $140(6.3)$ & $500(2.3)$ & 1.66 (1.34 to 2.06$)$ & $1.56(1.24$ to 1.97$)$ & \\
\hline Duration $\ddagger>90$ days & $227(10.3)$ & $1381(6.3)$ & $1.00(0.84$ to 1.20$)$ & 1.01 (0.84 to 1.23$)$ & \\
\hline
\end{tabular}

ACE=angiotensin converting enzyme; NSAID=non-steroidal anti-inflammatory drug.

*Within 90 days before index date; current users of other antihypertensive drugs and past users (>90 days before index date) of double and triple therapy combinations are not shown but were considered in regression model.

†Adjusted for covariates listed in table 1.

łLength of exposure to double or triple therapy combination. 


\section{Figure}

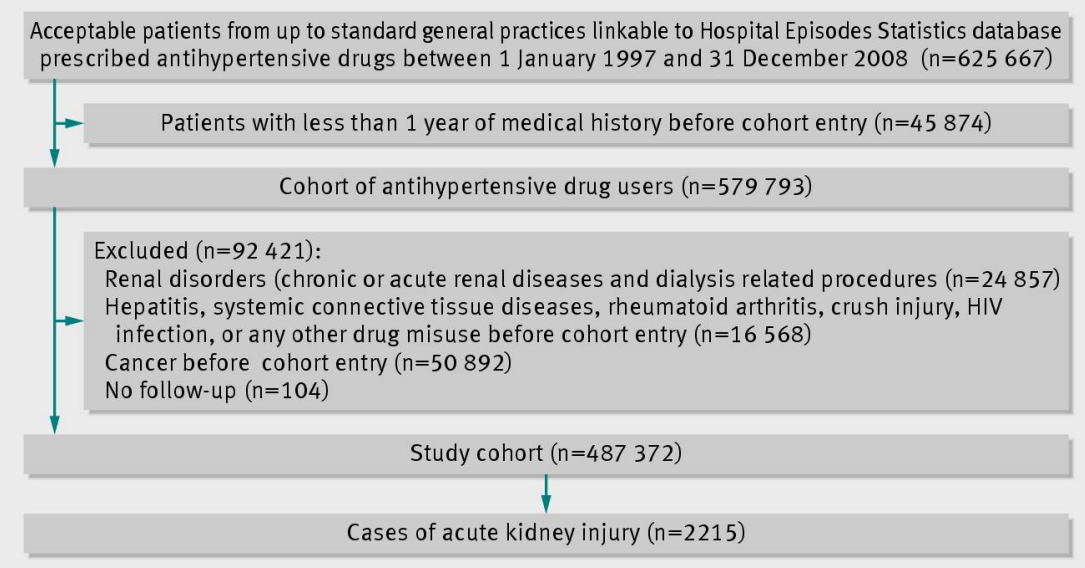

Flow chart of study 